\section{EPR of $\mathrm{Gd}^{3+}$ in Hydrated Double Nitrate Single Crystals}

\section{K. Jain}

Department of Physics, Indian Institute of Technology, Kanpur 208 016, India

Z. Naturforsch. 33a, 1389-1391 (1978);

received June 3, 1978

$\mathrm{EPR}$ of $\mathrm{Gd}^{3+}$ in $\mathrm{Sm}_{2} \mathrm{Zn}_{3}\left(\mathrm{NO}_{3}\right)_{12} \cdot 24 \mathrm{H}_{2} \mathrm{O}$ and $\mathrm{Pr}_{2} \mathrm{Mg}_{3}\left(\mathrm{NO}_{3}\right)_{12} \cdot 24 \mathrm{H}_{2} \mathrm{O}$ single crystals has been studied at $\mathrm{X}$-band. In addition to the allowed fine structure lines $(\Delta M= \pm 1)$ some weak low field lines identified as $\Delta M= \pm 2$ transitions, have been observed.

The electron paramagnetic resonance (EPR) of $\mathrm{Gd}^{3+}$ has been previously studied in single crystals of hydrated double nitrates, $\mathrm{M}_{2}{ }^{\prime \prime} \mathrm{M}_{3}{ }^{\prime \prime}\left(\mathrm{NO}_{3}\right)_{12}$ - $24 \mathrm{H}_{2} \mathrm{O}\left(\mathrm{M}^{\prime \prime \prime}=\mathrm{La}, \mathrm{Bi}\right.$ and $\left.\mathrm{M}^{\prime \prime}=\mathrm{Mg}, \mathrm{Zn}\right)[1,2]$ and in $\operatorname{Pr}_{2} \mathrm{Zn}_{3}\left(\mathrm{NO}_{3}\right)_{12} \cdot 24 \mathrm{H}_{2} \mathrm{O}$ [3]. However, the weak lines which occur at the low magnetic field side of the allowed $(\Delta M= \pm 1)$ fine structure lines in the EPR spectra of $\mathrm{Gd}^{3+}$ in double nitrates have not been investigated previously. As will be shown in this paper these lines have been identified as arising from the higher order EPR transitions $(|\Delta M|>1)$. This paper describes the EPR of $\mathrm{Gd}^{3+}$ in

$$
\begin{array}{ll}
\mathrm{Sm}_{2} \mathrm{Zn}_{3}\left(\mathrm{NO}_{3}\right)_{12} \cdot 24 \mathrm{H}_{2} \mathrm{O} & (\mathrm{SZN}) \\
\mathrm{Pr}_{2} \mathrm{Mg}_{3}\left(\mathrm{NO}_{3}\right)_{12} \cdot 24 \mathrm{H}_{2} \mathrm{O} & (\mathrm{PMN})
\end{array}
$$

single crystals from $300 \mathrm{~K}$ to $77 \mathrm{~K}$.

The crystal structure of $\mathrm{Ce}_{2} \mathrm{Mg}_{3}\left(\mathrm{NO}_{3}\right)_{12} \cdot 24 \mathrm{H}_{2} \mathrm{O}$ has been determined by Zalkin et al. [4]. The SZN and the PMN can be expected to have similar structure. The primitive cell containing one formula unit is rhombohedral with space group $\mathrm{R} \overline{3}$ $[4,5]$. The unit cell contains three divalent ions situated at two different lattice sites with point symmetry $\mathrm{C}_{3}$ and $\mathrm{C}_{\mathrm{i}}$. The trivalent ions are found at sites of $\mathrm{C}_{\mathrm{i}}$ point symmetry and the rest of the atoms are in positions of the general type. Culvahouse et al. [6] have shown that there are two trivalent ions along the long diagonal of the rhombohedron and $5.48 \AA$ to either side of the centre of the cell. The long diagonal of the rhombohedron is along the trigonal axis. Each trivalent ion is coordinated with 12 oxygens belonging to six nitrate ions, located at the corners of a somewhat irregular icosahedron.

Single crystals of SZN and PMN doped with $\mathrm{Gd}^{3+}$ were grown at room temperature by slow evaporation of aqueous solutions of $\mathrm{M}^{\prime \prime \prime}\left(\mathrm{NO}_{3}\right)_{3}$ - $6 \mathrm{H}_{2} \mathrm{O} \quad\left(\mathrm{M}^{\prime \prime \prime}=\mathrm{Sm}, \mathrm{Pr}\right)$ and $\mathrm{M}^{\prime \prime}\left(\mathrm{NO}_{3}\right)_{2} \cdot 6 \mathrm{H}_{2} \mathrm{O}$ $\left(\mathrm{M}^{\prime \prime}=\mathrm{Zn}, \mathrm{Mg}\right)$ mixed in stoichiometric ratios. The $\mathrm{Gd}^{3+}$ was introduced into the host lattices by adding a small amount $(0.2 \%$ by weight $)$ of $\mathrm{Gd}\left(\mathrm{NO}_{3}\right)_{3} \cdot 6 \mathrm{H}_{2} \mathrm{O}$. The crystals grow in flat hexagonal plates, the plane of which is perpendicular to the trigonal axis [7]. A Varian V-4502 $\mathrm{X}$-band EPR spectrometer with a 9 -inch magnet and $100 \mathrm{kHz}$ field modulation was used to record the spectra. As a reference for the magnetic field strength, the resonance line of DPPH with $g=$ 2.0036 was used.

For an arbitrary orientation of the crystal, the EPR spectrum consists of a single set of seven lines between $\sim 0.25 \mathrm{~T}$ and $\sim 0.43 \mathrm{~T}$ which arise from the allowed fine structure transitions $(\Delta M=$ \pm 1 ) of the $\mathrm{Gd}^{3+}$ centre (formed by the substitution of $\mathrm{M}^{\prime \prime \prime}$ by $\mathrm{Gd}^{3+}$ ). In addition to these lines there are many weak lines below $\sim 0.24 \mathrm{~T}$ (Figure 1 ). Angular variation studies of the spectrum reveal the following:

1. The maximum spread of the spectrum ( $z$ axis) corresponding to $\Delta M= \pm 1$ transitions occurs when the external magnetic field is parallel to the trigonal axis ( $c$ axis) of the crystal. This axis can be located accurately from the external morphology of the crystal.

2. The subsidiary maxima ( $x$ axis) occur when the external magnetic field is approximately perpendicular to the $c$ axis. However, when the field is at $90^{\circ}$ to $c$ axis, all the observed transitions do not attain an extremum. The departure from

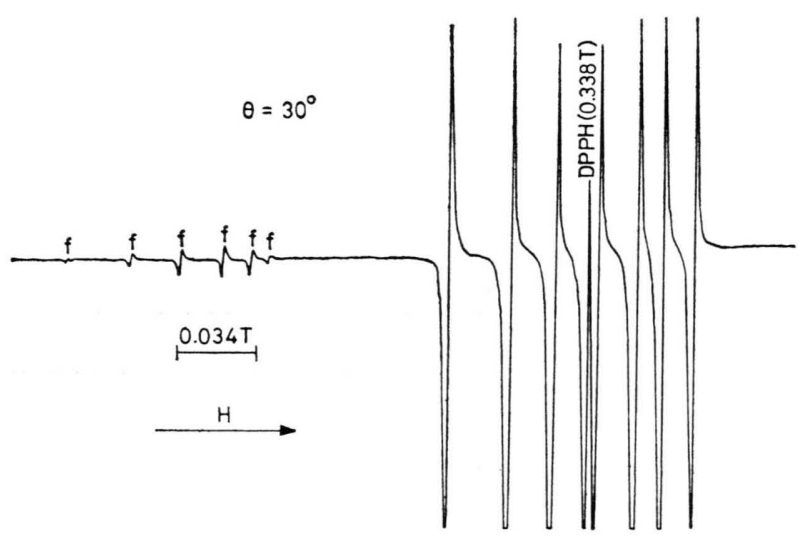

Fig. 1. EPR spectrum of $\mathrm{Gd}^{3+}$ in $\mathrm{Sm}_{2} \mathrm{Zn}_{3}\left(\mathrm{NO}_{3}\right)_{12} \cdot 24 \mathrm{H}_{2} \mathrm{O}$ single crystals at $300 \mathrm{~K}$; with $H$ makes an angle $30^{\circ}$ to the $z$ axis in the $z x$ plane. Forbidden fine structure lines are marked $f$. 
the perpendicular direction is as much as $\sim 6^{\circ}$ and the corresponding change in field position is $\sim 0.001 \mathrm{~T}$ which is more than the experimental error.

3 . The spectrum shows a periodicity of $\pi / 3$, when the crystal is rotated in the plane perpendicular to the $c$ axis. However, in this plane the angular variation of line positions is very small, therefore the site symmetry can be treated as being practically trigonal.

The spin-Hamiltonian for $\mathrm{Gd}^{3+}$ corresponding to a trigonal symmetry and with the $z$ axis parallel to the $c$ axis can be written as [8]

$$
\begin{aligned}
\mathscr{H}= & g \beta S \cdot H+\frac{1}{3} b_{2}{ }^{0} O_{2}{ }^{0}+\frac{1}{60} b_{4}{ }^{0} O_{4}{ }^{0} \\
& +\frac{1}{1260} b_{6}{ }^{0} O_{6}{ }^{0}+\frac{1}{3} b_{4}{ }^{3} O_{4}{ }^{3} \\
& +\frac{1}{36} b_{6}{ }^{3} O_{6}{ }^{3}+\frac{1}{1260} b_{6}{ }^{6} O_{6}{ }^{6}
\end{aligned}
$$

where the symbols have their usual meaning. The crystal field parameters $b_{4}{ }^{3}$ and $b_{6}{ }^{3}$ are identically zero for $\mathrm{C}_{3 \mathrm{~h}}$ and $\mathrm{D}_{3 \mathrm{~d}}$ symmetry and not zero for $\mathrm{C}_{3 \mathrm{v}}$ symmetry [2].

To find the parameters of the spin-Hamiltonian (1) we have used the approximate equations for $H \| z$ given in [1]. With these equations we determine the parameters $b_{2}{ }^{0}, b_{4}{ }^{0}, b_{6}{ }^{0}$ and $g_{\|}$. The absolute value of the constant $b_{6}{ }^{6}$ was found from the variation of the position of lines at $H \perp z$ axis. The parameters for $\mathrm{Gd}^{3+}$ in SZN and PMN at $300 \mathrm{~K}$ and $77 \mathrm{~K}$ are given in Table 1 . The signs of the parameters $b_{n}{ }^{m}$ given in this table are only relative and have been determined assuming $b_{2}{ }^{0}$ to be positive.
To identify the observed low field lines we have investigated higher order EPR transitions $(|\Delta M|$ $>1$ ) for the $\mathrm{Gd}^{3+}$ centre. For this purpose we have evaluated the positions of all the fine structure transitions. The approximate theoretical expressions for the angular variation of line positions were obtained by considering the predominant $b_{2}{ }^{0} \mathrm{O}_{2}{ }^{0}$

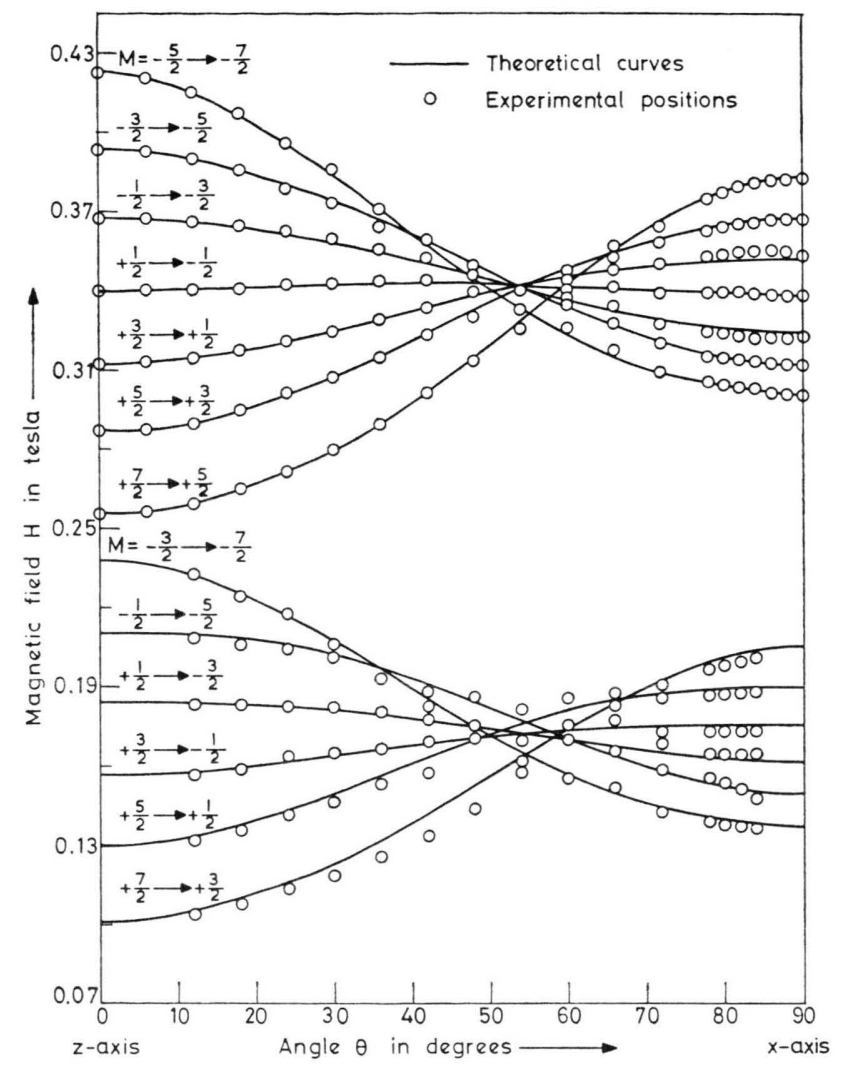

Fig. 2. Angular dependence of $\mathrm{Gd}^{3+} \mathrm{EPR}$ lines in the $z x$ plane for $\mathrm{Sm}_{2} \mathrm{Zn}_{3}\left(\mathrm{NO}_{3}\right)_{12} \cdot 24 \mathrm{H}_{2} \mathrm{O}$ at $300 \mathrm{~K}$.

Table 1. Spin-Hamiltonian parameters for $\mathrm{Gd}^{3+}$ in $\mathrm{Sm}_{2} \mathrm{Zn}_{3}\left(\mathrm{NO}_{3}\right)_{12} \cdot 24 \mathrm{H}_{2} \mathrm{O}$ and

\begin{tabular}{|c|c|c|c|c|}
\hline \multirow{2}{*}{$\begin{array}{l}\text { Spin- } \\
\text { Hamiltonian } \\
\text { parameters }\end{array}$} & \multicolumn{2}{|c|}{$\mathrm{Sm}_{2} \mathrm{Zn}_{3}\left(\mathrm{NO}_{3}\right)_{12} \cdot 24 \mathrm{H}_{2} \mathrm{O}$} & \multicolumn{2}{|c|}{$\mathrm{Pr}_{2} \mathrm{Mg}_{3}\left(\mathrm{NO}_{3}\right)_{12} \cdot 24 \mathrm{H}_{2} \mathrm{O}$} \\
\hline & $300 \mathrm{~K}$ & $77 \mathrm{~K}$ & $300 \mathrm{~K}$ & $77 \mathrm{~K}$ \\
\hline $\begin{array}{l}b_{2}{ }^{0} \\
b_{4}{ }^{0} \\
b_{6}{ }^{0} \\
b_{6}{ }^{6}\end{array}$ & $\begin{aligned} & 126.6 \pm 0.5 \\
& 0.58 \pm 0.05 \\
& 0.48 \pm 0.05 \\
& 5.6 \pm 1\end{aligned}$ & $\begin{array}{c}137.6 \pm 0.5 \\
0.65 \pm 0.05 \\
0.74 \pm 0.05 \\
5.6 \pm 1\end{array}$ & $\begin{aligned} 113.7 & \pm 0.5 \\
0.29 & \pm 0.05 \\
0.44 & \pm 0.05 \\
4.6 & \pm 1\end{aligned}$ & $\begin{array}{c}123.2 \pm 0.5 \\
0.48 \pm 0.05 \\
0.79 \pm 0.05 \\
5.6 \pm 1\end{array}$ \\
\hline$g_{\|}$ & $\begin{array}{r}1.9917 \\
\pm 0.0005\end{array}$ & $\begin{array}{r}1.9917 \\
\pm 0.0005\end{array}$ & $\begin{array}{r}1.9922 \\
\pm 0.0005\end{array}$ & $\begin{array}{r}1.9922 \\
\pm 0.0005\end{array}$ \\
\hline$g_{\perp}$ & $\begin{array}{r}1.992 \\
\pm 0.002\end{array}$ & $\begin{array}{r}1.992 \\
\pm 0.002\end{array}$ & $\begin{array}{r}1.995 \\
\pm 0.003\end{array}$ & $\begin{array}{r}1.995 \\
\pm 0.003\end{array}$ \\
\hline
\end{tabular}
$\mathrm{Pr}_{3} \mathrm{Mg}_{3}\left(\mathrm{NO}_{3}\right)_{12} \cdot 24 \mathrm{H}_{2} \mathrm{O}$ at $300 \mathrm{~K}$ and $77 \mathrm{~K}$. The $b_{n}^{m}$ parameters are given in units of $10^{-4} \mathrm{~cm}^{-1}$. 
term up to second order of perturbation and the rest of the terms of the spin-Hamiltonian only up to first order. Figure 2 shows the angular variation of the spectrum in the $z x$ plane. In the figure $\Theta$ is the angle between the external magnetic field and the $z$ axis. The reasonably good agreement of the calculated angular variation with the experimental

[1] R. S. Trenam, Proc. Phys. Soc. London A 66, 118 (1953).

[2] H. A. Buckmaster, J. C. Dering, and J. I. Fry, J. Phys. C 1, 599 (1968).

[3] V. K. Jain and T. M. Srinivasan, Pramana 10, 155 (1978).

[4] A. Zalkin, J. D. Forrester, and D. H. Templeton, J. Chem. Phys. 39, 2881 (1963). one suggests that the weak lines at the low magnetic field side of the allowed $(\Delta M= \pm 1)$ fine structure lines (Fig. 1) are due to $\Delta M= \pm 2$ transitions.

\section{Acknowledgements}

The author is thankful to the CSIR (Pool), New Delhi for financial assistance.

[5] M. R. Anderson, G. J. Jenkin, and J. W. White, Acta Cryst. B 33, 3933 (1977).

[6] J. W. Culvahouse, W. Unruh, and R. C. Sapp, Phys. Rev. 121, 1370 (1961).

[7] R. A. Fisher, Rev. Sci. Instrum. 43, 386 (1972).

[8] H. A. Buckmaster and Y. H. Shing, Phys. Stat. Sol. (a) 12, 325 (1972). 